\title{
ADVANCES
}

\section{Data collection on patients in emergency departments in Canada}

\author{
Brian H. Rowe, MD, MSc; ${ }^{* \dagger}$ Kenneth Bond, MA; ${ }^{\dagger}$ Maria B. Ospina, MSc; ${ }^{\dagger}$ Sandra Blitz, MSc; ${ }^{*}$ \\ Michael Schull, MD, MSc; $\ddagger$ Douglas Sinclair, MD;§ Michael Bullard, MD*
}

\begin{abstract}
Objective: Relatively little is known about the ability of Canadian emergency departments (EDs) and the federal, provincial and territorial governments to quantify ED activity. The objectives of this study were to determine the use of electronic patient data in Canadian EDs, the accessibility of provincial data on ED visits, and to identify the data elements and current methods of ED information system (EDIS) data collection nationally.

Methods: Surveys were conducted of the following 3 groups: 1) all ED directors of Canadian hospitals located in communities of $>10000$ people, 2) all electronic EDIS vendors, and 3) representatives from the ministries of health from 13 provincial and territorial jurisdictions who had knowledge of ED data collection.

Results: Of the 243 ED directors contacted, 158 completed the survey (65\% response rate) and $39 \%$ of those reported using an electronic EDIS. All 11 EDIS vendor representatives responded. Most of the vendors provide a similar package of basic EDIS options, with add-on features. All 13 provincial or territorial government representatives completed the survey. Nine (69\%) provinces and territories collect ED data, however the source of this information varies. Five provinces and territories collect triage data, and 3 have a comprehensive, jurisdiction-wide, population-based ED database. Thirty-nine percent of EDs in larger Canadian communities track patients using electronic methods. A variety of EDIS vendor options are available and used in Canada.

Conclusion: The wide variation in methods and in data collected presents serious barriers to meaningful comparison of ED services across the country. It is little wonder that the majority of information regarding ED overcrowding in Canada is anecdotal, when the collection of this critical health information is so variable. There is an urgent need to place the collection of ED information on the provincial and national agenda and to ensure that the collection of this information consistent, comprehensive and mandatory.
\end{abstract}

Key words: emergency departments; EDIS; emergency department information system; databases; medical records

\footnotetext{
*Department of Emergency Medicine, University of Alberta, Edmonton, Alta.

tEvidence-Based Practice Centre, University of Alberta, Edmonton

‡Division of Emergency Medicine, University of Toronto, and Institute of Clinical Evaluative Sciences, Toronto, Ont. §Department of Emergency Medicine, Dalhousie University, Halifax, NS
}

Presented in part at the 11th International Conference on Emergency Medicine, June 3-7, 2006, in Halifax, NS.

Received: July 19, 2006: revisions received: Sept. 12, 2006; accepted: Sept. 12, 2006

This article has been peer reviewed.

Can J Emerg Med 2006;8(6):417-24 


\begin{abstract}
RÉSUMÉ
Objectif : Au Canada, on sait relativement peu de choses au sujet de la capacité qu'ont les services d'urgence $(\mathrm{SU})$ et les gouvernements fédéral, provinciaux et territoriaux à quantifier l'activité des SU. Cette étude visait à déterminer l'utilisation de données électroniques sur les patients dans les SU du Canada et l'accessibilité des données provinciales sur les visites aux SU, ainsi qu'à définir les éléments de données et les méthodes courantes de collecte de données des systèmes d'information des SU (SISU) à l'échelle nationale.

Méthodes: On a effectué des sondages auprès des trois groupes suivantes : 1) tous les directeurs de SU d'hôpitaux canadiens situés dans des localités de $>10000$ habitants, 2) tous les fournisseurs de SISU électroniques et 3) les représentants des ministères de la Santé de 13 administrations provinciales et territoriales qui avaient des connaissances de la collecte de données sur les SU.

Résultats: Sur les 243 directeurs de SU avec lesquels on a communiqué, 158 ont répondu au sondage (taux de réponse de $65 \%$ ) et $39 \%$ de ceux-ci ont déclaré utiliser un SISU électronique. Tous les représentants des fournisseurs de SISU (11) ont répondu. La plupart des fournisseurs offrent un ensemble semblable d'options de base de SISU assorti de caractéristiques supplémentaires. Les représentants des 13 gouvernements provinciaux et territoriaux ont répondu au sondage. Neuf (69\%) provinces et territoires recueillent des données sur les SU, mais les sources de cette information varient. Cinq provinces et territoires recueillent des données de triage et trois ont une base de données représentative, intégrée, provinciale ou territoriale sur les SU; $39 \%$ des SU des grandes localités du Canada suivent les patients par des moyens électroniques. Tout un éventail d'options offertes par les fournisseurs de SISU sont disponibles et utilisées au Canada.

Conclusion: La variation importante des méthodes de collecte et des données recueillies nuit sérieusement à une comparaison significative entre les SU au Canada. II ne faut donc pas s'étonner que la majeure partie de l'information portant sur l'engorgement des SU au Canada soit anecdotique puisque la collecte de ces données critiques sur la santé varie énormément. Il est urgent d'inscrire la collecte d'information sur les SU au programme provincial et national et de veiller à ce que la collecte de ces données soit uniforme, intégrée et obligatoire.
\end{abstract}

\section{Introduction}

The ability of local, provincial, territorial and national organizations to quantify emergency department (ED) activity and provide data on ED overcrowding depends on good quality, easily accessible and real-time information. Although a variety of sources are available for estimating ED censuses and activity (e.g., data on mortality, hospitalization, physician billing and on ED patients, and in-hospital databases and electronic ED information systems [EDIS]), most are of little value in providing data for assessing ED processes, activity or overcrowding. Inconsistent reporting of ED data at the hospital (i.e., local), regional, provincial and national levels impairs the ability of the federal, provincial and territorial governments to monitor and understand ED use and problems, such as overcrowding, that occur across their jurisdictions. This deficiency hinders attempts to define the causes, characteristics and impacts of ED overcrowding and to develop effective solutions.

Identifying methods of valid data collection (electronic or otherwise) in EDs, pinpointing information gaps, determining capabilities of provincial ED databases, and examining contributions to a common database are important steps in understanding how ED activity is recorded in
Canada. This knowledge will assist in developing a standardized approach for measuring ED overcrowding that would allow comparison between EDs of different sizes and capacities. A better understanding of ED use and the degree of ED overcrowding could improve communication among the many individuals and organizations that use this information for decision-making. The goal of this report was to survey Canadian hospital ED directors, EDIS vendors, and representatives from the ministries of health from the 13 provincial and territorial jurisdictions and the national health data repository (Canadian Institute for Health Information $[\mathrm{CIHI}]$ ) to obtain information on the common EDIS being used in Canada, the options available to Canadian EDs and their level of use, the accessibility of provincial data on ED visits, and the data elements and methods of EDIS data collection at the national level.

\section{Methods}

\section{Survey of hospital ED directors}

A national cross-sectional survey ED directors with regard to ED overcrowding was completed between March and June 2005; it has been described elsewhere 1 and will be briefly described here. The survey involved 243 ED direc- 
tors of hospitals located in Canadian municipalities (from all provinces and territories) with a population $>10000$. A 54-item questionnaire was developed in both English and French from existing national and international ED overcrowding surveys, and piloted using standard techniques. Two delivery formats were used: a Web-based survey distributed by an automated email system and a paper form distributed by mail. Two reminders were sent. In this report, we examined the associations between site characteristics and EDIS availability.

\section{Survey of EDIS vendors}

This cross-sectional study surveyed EDIS vendor representatives familiar to a panel of experts in emergency medicine who were aware of EDIS vendor activities at a provincial and national level in addition to those identified by an Internet search of EDIS vendors available in Canada. This Technical Expert Panel represented 5 provinces, ED-based information technology experts, researchers, emergency physicians, ED administrators, and a nurse manager (Appendix 1). The same Panel and a research team (which included experts in emergency medicine other than those identified as members of the Panel) generated a list of potential questions. A pilot survey was sent to a convenience sample of the Panel members to test the completion time and comprehensiveness of the questionnaire. Pilot respondents were asked to add questions they considered important that had not been included. Several substantive changes were made before the final questionnaire was approved.

A final 1-page survey was emailed or faxed to the EDIS vendors and to clinicians familiar with the product. These clinicians were identified by a member of the research team or a Panel member as having a working knowledge of the EDIS software and as working in an institution that used the software at the time of the survey. (An attempt was made to verify information by comparing vendors' responses with those of the clinicians. In cases where there was a discrepancy between the 2 , the clinician noted that the full capabilities of the software were not being used and the vendor's response was accepted as accurate.) A covering letter described the background of the original ED overcrowding study ${ }^{1}$ and the rationale for the survey. Information on the use of EDIS products in Canada, the availability of standard EDIS tools (e.g., maps, triage function) and added features (e.g., patent order entry, electronic charting) was requested.

This survey was conducted between May and September 2005. We examined only software that was available in North America and that had been developed specifically for ED data capture; therefore, vendors who stated that they did not have a stand-alone ED module were excluded from the survey. Up to 3 reminders were sent. The search identified 11 potential participants from the private sector. All the EDIS vendor representatives contacted agreed to participate.

\section{Survey of federal/provincial/territorial representatives}

A cross-sectional study of representatives of the ministries of health in each province and territory in Canada was conducted. The Panel identified representatives familiar with the provincial ED data collection and the National Ambulatory Care Record System (NACRS) housed at CIHI. A CIHI representative completed a survey for NACRS.

As with the two surveys described above, the Panel and the research team generated a list of questions, and a pilot survey was sent to a convenience sample of the Panel members to ascertain completion time and determine its comprehensiveness. Pilot respondents were asked to add questions they considered important that had not been included. Several substantive changes were made at this stage.

A final 1-page survey was emailed to each federal, provincial and territorial representative and, when possible, to an emergency clinician or researcher familiar with provincial data collection. A covering letter described the background of the original ED overcrowding study ${ }^{1}$ and the rationale for the present survey. Information on the methods of ED data collection, annual reporting, triage recording, and contribution to NACRS was requested. The survey also asked whether changes to information collection systems were expected in the near future. Provincial representatives were asked information regarding important data elements. Up to 3 reminders were sent.

This survey was also conducted between May and September 2005. The search identified 10 potential provincial representatives, 3 potential territorial representatives and 1 federal representative from the public sector with knowledge of federal/provincial/territorial ED capabilities. Each representative was contacted and agreed to participate.

\section{Statistics}

The ED directors' survey database was imported to SAS for Windows (v. 8.2; SAS Institute, Cary, NC) for statistical analysis; data for all other surveys were entered into Excel 2003 (Microsoft Corporation, Redmond, Wash.). All available data were summarized regardless of the completeness of an individual survey. Data for the 3 surveys were summarized as percentages for categorical variables. 
Continuous data are reported as means with standard deviations, or as medians with interquartile ranges, when appropriate.

\section{Ethics}

The Health Research Ethics Board of the University of Alberta approved the 3 survey protocols. Consent to participate in all of the surveys was assumed if the questionnaire was completed and returned. The data were coded, and the

\begin{tabular}{|c|c|}
\hline $\begin{array}{l}\text { System(s) available } \\
\text { at your hospital }\end{array}$ & $\begin{array}{l}\text { No. (and \%) } \\
\text { of hospitals }\end{array}$ \\
\hline Electronic EDIS & $57 / 158(39)$ \\
\hline \multicolumn{2}{|l|}{ Type of EDIS } \\
\hline iSoft & $12 / 57(21)$ \\
\hline SIURGE & $11 / 57(19)$ \\
\hline Cerner & 9/57 (16) \\
\hline MEDITECH & $10 / 57(18)$ \\
\hline Other & $12 / 57(21)$ \\
\hline Triage scoring system & 146/148 (99) \\
\hline \multicolumn{2}{|l|}{ Type of triage system } \\
\hline CTAS & $138 / 146(95)$ \\
\hline Manchester & 2/146 (1) \\
\hline Other & 4/146 (3) \\
\hline Electronic triage system & 28/146 (19) \\
\hline \multicolumn{2}{|c|}{$\begin{array}{l}\text { EDIS = emergency department information } \\
\text { systems; CTAS = Canadian Emergency } \\
\text { Department Triage and Acuity Scale }\end{array}$} \\
\hline
\end{tabular}

anonymity of the participants was maintained in reporting aggregate results.

\section{Results}

\section{Survey of hospital ED directors}

For the ED directors, 158 of the 243 (65\%) responded. Of the 158, 57 (39\%) reported using an electronic EDIS system. A small number of EDIS vendors provide the majority of products to these 57 EDs: iSoft Corporation (Dallas, Tex.), SIURGE (Logibec Groupe Informatique Ltd., Montréal), Cerner Canada Limited (London, Ont.) and MEDITECH (Medical Information Technology, Inc., Westwood, Mass.). Triage was conducted in $99 \%$ of the 57 EDs, with the Canadian Emergency Department Triage and Acuity Scale (CTAS) ${ }^{2}$ the scale most commonly used. Electronic triage was available in $19 \%$ of the 57 EDs (Table 1).

\section{Survey of EDIS vendors}

This survey had a $100 \%$ response rate, and 7 of the 11 vendors reported that their software was currently being used in Canadian EDs (Table 2). Ten (91\%) of the vendors provide similar packages of basic EDIS options (tracking and mapping functions and electronic triage). Although options for triage varied, 8 provided a CTAS option. More advanced informatics (e.g., electronic charts, discharge information, order entry) were less commonly available or were available only as add-on features. Overall, 7 EDIS vendors

Table 2. Emergency department information systems vendor responses to the survey $(n=11)$

\begin{tabular}{|c|c|c|c|c|c|c|c|}
\hline Company & $\begin{array}{c}\text { Canadian } \\
\text { use }\end{array}$ & Triage system & eTriage & POE & eCharts & $\mathrm{D} / \mathrm{Cl}$ & $\begin{array}{l}\text { Other } \\
\text { features }\end{array}$ \\
\hline iSoft* & Yes & CTAS; Manchester & Yes & Yes & Add-on & Add-on & Yes \\
\hline SIURGE* & Yes & non-CTAS & Yes & No & No & No & No \\
\hline Cerner Canada Limited & Yes & CTAS; Manchester; ESI & Yes & Yes & Add-on & Add-on & No \\
\hline MEDITECH* & Yes & CTAS; others & Yes & Yes & Yes & Add-on & No \\
\hline McKesson Canada & Yes & CTAS & Yes & Yes & Add-on & Yes & No \\
\hline Eclipsys & Yes & CTAS & Yes & Yes & Yes & Yes & Yes \\
\hline Wellsoft Corporation & Yes & Other & Yes & Yes & Yes & Yes & Yes \\
\hline $\begin{array}{l}\text { Amelior Patient Care } \\
\text { Technology Systems }\end{array}$ & No & CTAS & Yes & Yes & Add-on & Add-on & Yes \\
\hline T-Systems Enterprise Services & No & Customized & Yes & No & Yes & Yes & Yes \\
\hline Picis, Inc. & No & Customized & Yes & Yes & Add-on & Yes & Yes \\
\hline Total no. of vendors (and \%) & $7(64)$ & 8 CTAS (73) & $10(91)$ & $9(82)$ & $4(36)$ & $5(45)$ & $7(64)$ \\
\hline \multicolumn{8}{|c|}{$\begin{array}{l}\text { Note: All companies surveyed provided Tracking and Mapping with their product. } \\
\text { eTriage = electronic triage; POE = physician order entry; eCharts = electronic charts; D/CI = electronic discharge instructions; CTAS = Canadian Emergency } \\
\text { Department Triage and Acuity Scale; Add-on = not part of the main software package; ESI = Emergency Severity Index } \\
\text { *For manufacturing information, see Results section. }\end{array}$} \\
\hline
\end{tabular}


described other available options in addition to the core EDIS functions.

\section{Survey of federal/provincial/territorial representatives}

All government representatives responded to the survey (Table 3). Nine provinces and territories reported collecting specific ED information. The source of these data varies: 7 of the 9 obtained all or part of their data from medical records at each site. Three reported that they produce an annual ED report (Ontario, Quebec, Nunavut), and 3 have a comprehensive, jurisdiction-wide ED database (Alberta, Yukon, Ontario).

A variety of data are collected and reported by provinces and territories (Table 4). All jurisdictions reported the ability to determine total ED volumes, although the methods employed and the ease of use varied. Outcomes are variably linked to the ED registration data; 9 jurisdictions
(69\%) can access admission status, and $8(62 \%)$ can access death records. Five jurisdictions (38\%) reported collecting triage data, 3 (23\%) collected presenting complaint data (e.g., chest pain) and 2 (15\%) coded reason-for-visit data (e.g., referral, follow-up). From the standpoint of common measures of ED overcrowding, 8 jurisdictions (62\%) were capable of providing length of ED stay for admitted patients, $6(46 \%)$ could provide percentages of ED patients leaving without being seen, 6 (46\%) could provide length of stay data for discharged patients, and $5(38 \%)$ could provide percentages of patients who left against medical advice. Fewer provinces and territories reported the ability to provide any data on episodes of ambulance diversion (4, or $31 \%)$ or waiting times in the $\mathrm{ED}(3$, or $23 \%)$.

Only 2 jurisdictions (Ontario, Yukon) provide comprehensive ED data to a national database (Table 3); however, at least 2 other provinces collect these data at selected sites and provide them to CIHI (British Columbia, Nova Sco-

Table 3. Federal/provincial/territorial ministries of health responses to the administrative databases survey

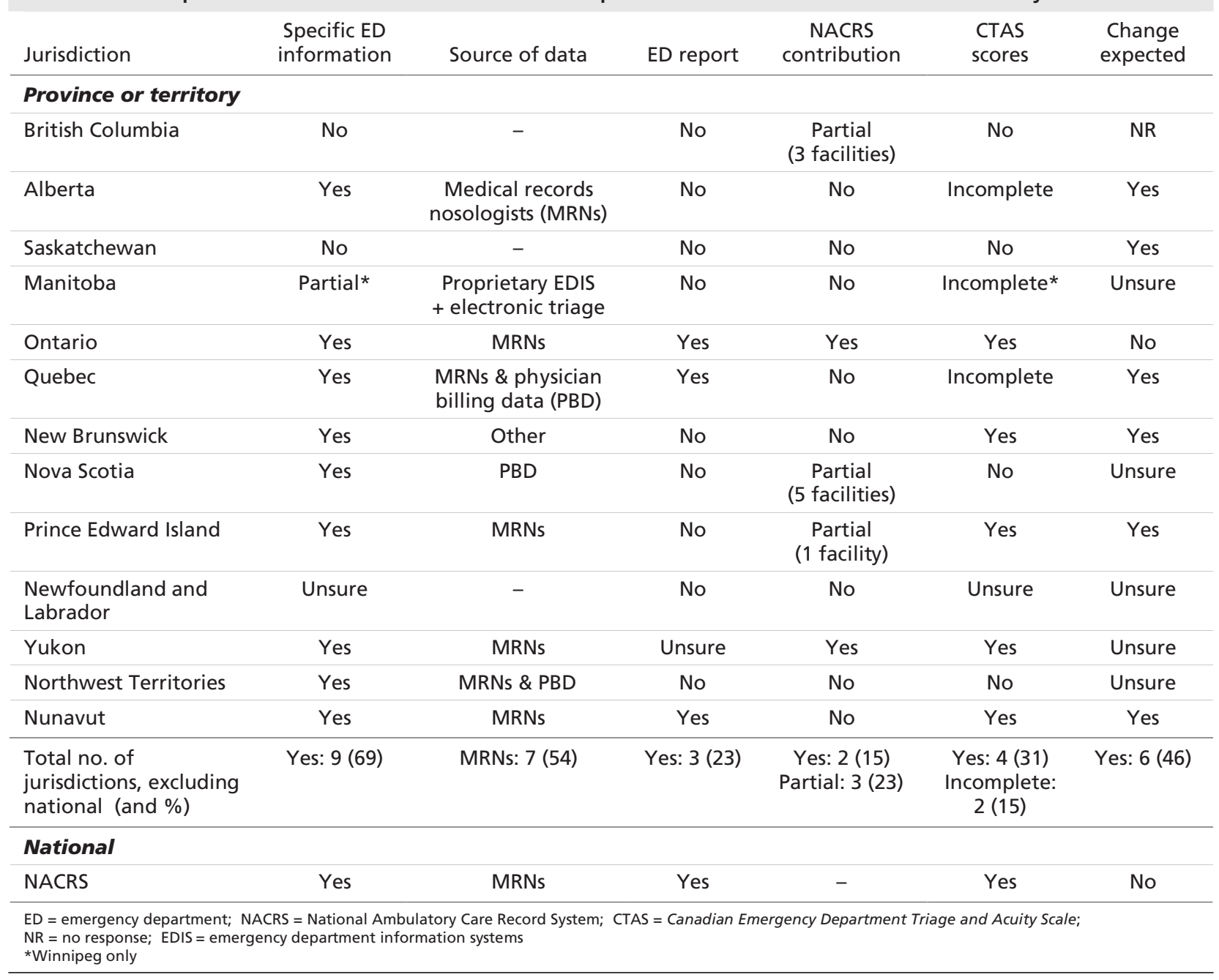


tia). Changes are expected in ED data collection by 5 provinces and 1 territory. NACRS is the sole national repository for ED information, although a low rate of contributions from the provinces ( 1 fully, 2 partially, 7 not at all) and territories (1 fully, 2 not at all) limits its utility as a national database.

\section{Discussion}

Information technology is rapidly being incorporated into medical practice, especially in the ED, where electronic diagnostic imaging, tracking and registration application are available. In the first national survey of ED directors, 39\% reported using an electronic EDIS in 2005, with the balance using paper-based methods. ${ }^{1}$ Although in the present survey we identified 11 vendors selling EDIS tools, no single vendor has a monopoly in Canada. In contrast, iSoft is used in over 70\% of Australian EDs (Amyn Harari, iSoft Canada, personal communication: June 2006). Perhaps most alarmingly, provincial and national surveillance of ED activity is embarrassingly deficient: most provinces rely on low-quality retrospective data collection; less than half can describe the population that leaves without being seen by a physician; and presenting complaints are captured in less than $25 \%$ of provinces. Valid and reliable data acquisition has a strategic role to play in understanding ED processes, addressing the ED overcrowding crisis in Canada, and other quality assurance processes. The lack of high quality provincial data makes finding the solutions to these critical issues far more difficult.

Even when data are presumably collected, their quality is suspect. For example, triage scores are an important measure of acuity and a useful predictor of resource use, the need for consultations, the need for admission, and overall costs. ${ }^{2.3}$ Triage is performed in most Canadian EDs, and CTAS is the most common rating system in place in Canada; however, only $19 \%$ of EDs reported using electronic triage. ${ }^{4}$ More widespread incorporation of electronic triage with built-in decision support could improve triage reliability ${ }^{4}$ and strengthen the validity of comparisons of patient acuity and complexity. ${ }^{2}$

Most EDIS vendors provide similar packages of basic EDIS options (such as tracking, mapping and triage capabilities); however, more advanced informatics (e.g., electronic charts, discharge information, order entry) are less commonly available and often only as add-on features. Given the availability of these options, it is disappointing to see that so few ED directors report their sites using them. EDs without an electronic EDIS may find it more difficult to generate comprehensive data on delays in care, times in the ED, and more fine-grained patient care data such as consultations, laboratory ordering, outcomes -

\begin{tabular}{|c|c|c|}
\hline Can the province/territory provide the following information? & $\begin{array}{l}\text { No. of } \\
\text { Yes responses } \\
\text { (and \%) }\end{array}$ & $\begin{array}{l}\text { Other } \\
\text { notes }\end{array}$ \\
\hline Overall ED volumes for the jurisdiction? & $13(100)$ & \\
\hline ED volumes for individual hospital EDs across the jurisdiction? & $12(92)$ & \\
\hline Outcomes (e.g., admission/discharge)? & $9(69)$ & $1 \mathrm{NR}^{*}$ \\
\hline Deaths occurring in the ED? & $8+1$ partial (69) & \\
\hline $\begin{array}{l}\text { Overall length of stay for patients in the ED awaiting admission } \\
\text { (i.e., time from bed request to time of admission to ward)? }\end{array}$ & $8(62)$ & \\
\hline Percentage of patients who leave without being seen? & $6(46)$ & \\
\hline Overall length of stay per patient for discharged patients? & $5+1$ partial (46) & 1 unsure \\
\hline Percentage of patients who leave against medical advice? & $5(38)$ & \\
\hline Episodes of ambulance diversion at each hospital? & $3+1$ partial (31) & 2 unsure \\
\hline $\begin{array}{l}\text { Waiting times in the ED (e.g., time from triage to bed place- } \\
\text { ment or from registration to being seen by a physician [fractile } \\
\text { response time])? }\end{array}$ & $2+1$ partial $(23)$ & \\
\hline Patient presenting complaints (e.g., chest pain)? & $3(23)$ & \\
\hline $\begin{array}{l}\text { A reason for visit code (e.g., referred, first visit, scheduled } \\
\text { follow-up)? }\end{array}$ & $2(15)$ & \\
\hline
\end{tabular}


all important data that are required to understand ED overcrowding and to accurately evaluate interventions to reduce it. Although there is a critical need to increase the use of information systems in Canadian EDs, it is also important to implement user-friendly programs that don't impair ED operations, or else uptake may be slow and problematic.

Although more than half of the provinces and territories reported collecting some form of ED data from a variety of sources (from medical records), only 5 collect triage data; and only Alberta, Yukon and Ontario have a comprehensive provincial or territorial ED database. Only 1 province and 1 territory (Ontario, Yukon) provide comprehensive ED data to the current national database (i.e., NACRS), although 6 provinces and territories reported that, in the near future, they plan to change the way they collect ED data. Whether these changes will be sufficiently robust and comprehensive to justify inclusion in the national ED database managed by CIHI remains to be seen.

The quality and comprehensiveness of ED data being collected varied among provinces and territories. Seemingly important data elements such as presenting complaint, reason for visit and triage are rarely recorded at the provincial level, and important measures of overcrowding as identified by research are infrequently collected. For example, a recent Canadian report found that the most important measure of overcrowding was the percentage of the ED occupied by inpatients. ${ }^{5}$ This factor, referred to as "access block" or "emergency in-patients," has been an area of emerging research activity since its description by Richardson in $2001 .{ }^{6}$ Despite its importance, none of the provincial or territorial representatives reported collecting or being capable of reporting this kind of information. Other research has shown that few hospitals can provide this information easily. ${ }^{1}$ Moreover, although length-of-stay data are available, the components (e.g., time from triage/registration to bed placement, time of MD assessment, time of consultation) are infrequently recorded.

Despite the variability in the recording of ED information, several well-defined data elements already exist in provincial (Alberta, Ontario) and national (NACRS) databases. In addition, the Canadian Association of Emergency Physicians has established a Canadian EDIS (CEDIS) Working Group, which has made recommendations regarding the appropriate data elements to be included in future electronic EDIS. ${ }^{7}$ The CEDIS Group developed a chief complaint list, ${ }^{8}$ which has since been revised and expanded (www.caep.ca). In addition, the CEDIS Group has released a list of appropriate data elements to collect in the future. Although there are differences in elements, mandatory fields and data definitions between the CEDIS data set and the NACRS database, these 2 groups are collaborating to harmonize their needs (D.S.: personal observation).

Finally, the quality of provincial data collection needs to be carefully examined. The lowest quality we discovered were billing records provided by physicians working in EDs. These are notoriously poor and should only be used for coarse evaluation of trends. Retrospective chart review by medical record nosologists is a modest improvement, especially on diagnostic coding; however, its validity depends on the completeness of physician record-keeping. The prospective collection of data from EDIS remains the highest quality data, yet only $39 \%$ of all large hospitals employ this promising option. The overall goal of ED data collection should be to replace the current system of ED data collection as quickly as possible and move closer toward the CEDIS ideal.

\section{Limitations}

The surveys described here have several limitations. The survey of Canadian hospital ED directors had a response rate of $65 \%$, so there is a likelihood of a non-response bias affecting the results. An attempt was made to sample all EDs in large urban areas; however, the sample may also be biased by its omission of smaller hospitals. The surveys of EDIS vendors and of national, provincial and territorial representatives may suffer from bias because the outcomes were self-reported and were not verified by system testing or widespread survey confirmation. We only surveyed vendors with stand-alone EDIS modules, and hospital-based systems that adapt to ED needs may be under-represented. Furthermore, electronic triage is available in many vender options; however, providing the ability to insert a CTAS number electronically is different than providing sophisticated decision support for the user. In the case of the EDIS vendor survey, an attempt was made to verify information by comparing vendors' responses with those of ED clinicians who had reported expertise with the EDIS software. In cases where there was a discrepancy between the 2, the clinician had noted that the full capabilities of the software were not being used and the vendor's response was accepted as accurate. In addition, although all of the identified EDIS vendors responded, other vendors may exist who have products that are appropriate for the Canadian market. Overall, recent information technology changes locally or provincially may partially invalidate some data presented here, and the dynamic nature of data collection may limit the generalizability of these findings in the future. 


\section{Conclusions}

An understanding of the causes, consequences and potential solutions to ED overcrowding can only be gained through the efficient collection of valid, comprehensive, reliable and timely data contributed to local and provincial repositories. In light of this, a logical next step is for each province and territory in Canada to adopt the NACRS reporting standard as a minimum and make contributions to a national ED database mandatory. Refining the NACRS data elements to make them more closely resemble the CEDIS data elements would be another improvement. Such work would increase understanding of ED use and overcrowding and, ultimately, would improve the services provided in ED settings.

The wide variation in methods and data collected presents serious barriers to meaningful comparison of ED services across the country. It is little wonder that the majority of information regarding ED overcrowding in Canada is anecdotal, when the collection of this critical health information is so variable. There is an urgent need to place the collection of ED information on the provincial and national agenda and to make collecting this information consistent, comprehensive and mandatory.

Acknowledgements: We are grateful to the Canadian Agency for Drugs and Technologies in Health (CADTH; www.cadth.ca) for funding this project, and to those who served as members of the Technical Expert Panel for this report (Appendix 1). The Panel's expertise, contributions and thoughtful comments were invaluable for the development and completion of this project.

Competing interests: Dr. Schull holds a New Investigator Award from the Canadian Institutes of Health Research (CIHR); Dr. Rowe holds a Canada Research Chair from the Government of Canada. Dr. Sinclair (Chair) and Drs. Rowe and Bullard all sit on the Canadian Association of Emergency Physicians (CAEP) CEDIS Committee. The other authors disclose no conflicts of interest.

\section{References}

1. Rowe BH, Bond K, Ospina MB, et al. Frequency, determinants, and impact of overcrowding in emergency departments in Canada: a national survey of emergency department directors. Tech rep no 67.3. Ottawa: Canadian Agency for Drugs and Technologies in Health; 2006.

2. Beveridge R, Clarke B, Janes L, et al. Canadian Emergency Department Triage and Acuity Scale: implementation guidelines. Can J Emerg Med 1999;1(3 suppl). Online version available at: www.caep.ca (accessed 2006 Oct 12).

3. Dong SL, Bullard MJ, Meurer DP, et al. Emergency department triage: evaluating the validity of a computerized triage tool [abstract]. Can J Emerg Med 2004;6(3):209.

4. Grafstein EJ, Innes GD, Westman J, et al. The inter-rater reliability of triage in an acute care emergency department setting. Acad Emerg Med 2003;10:527.

5. Dong SL, Bullard MJ, Meurer DP, et al. Emergency triage: comparing a novel computer triage program with standard triage. Acad Emerg Med 2005;12:502-7.

6. Ospina MB, Bond K, Schull M, et al. Measuring overcrowding in emergency departments: a call for standardization. Tech rep no 67.1. Ottawa: Canadian Agency for Drugs and Technologies in Health; 2006.

7. Richardson DB. Association of access block with decreased ED performance. Acad Emerg Med 2001;8(5):575-6.

8. Innes G, Murray M, Grafstein E; for the Canadian Emergency Department Information System (CEDIS) working group. A consensus-based process to define standard national data elements for a Canadian emergency department information system. Can J Emerg Med 2001;3(4):277-84.

9. Grafstein E, Unger B, Bullard M, et al; for the Canadian Emergency Department Information System (CEDIS) Working Group. Canadian Emergency Department Information System (CEDIS) Presenting Complaint List (Version 1.0). Can J Emerg Med 2003;5(1):27-34.

Corresponding author (no reprints available): Dr. Brian H. Rowe, Department of Emergency Medicine, University of Alberta, Rm. 1G1.43 WMC, 8440 - 112th St., Edmonton AB T6G 2B7

Appendix 1. Technical Expert Panel members

- $\quad$ Terry Klassen, MD, MSc, FRCPC, Department of Pediatrics and Evidence-Based Practice Center, University of Alberta, Edmonton, Alta.

- $\quad$ Carla Policicchio, BScN, RN, National Emergency Nurses Affiliation, Edmonton

- $\quad$ Brian Holroyd, MD, FACEP, FRCPC, Department of Emergency Medicine, University of Alberta, Edmonton

- $\quad$ Gil Curry, MD, FRCPC, Department of Emergency Medicine, Calgary Health Region, Calgary, Alta.

- $\quad$ Sam Campbell, MB BCh, CCFP (EM), Department of Emergency Medicine, Dalhousie University, Halifax, NS

- $\quad$ Philip Yoon, MD, CCFP (EM), MBA, Department of Emergency Medicine, University of Alberta, Edmonton

- Marc Afilalo, MD, MCFP (EM), FACEP, FRCPC, Emergency Department, Sir Mortimer B. Davis-Jewish General Hospital, and Faculty of Medicine, McGill University, Montreal, Que.

- $\quad$ Grant Innes, MD, CCFP, FRCPC, Department of Emergency Medicine, Providence Health Care, St. Paul's Hospital, Vancouver, BC

- Mukarram Ali Zaidi, MB BS, MSc, Canadian Council on Health Services Accreditation, Ottawa, Ont. 